\title{
Evaluation of a Saudi major airport's medical preparedness for mass casualty incident: a mixed- methodology study
}

\begin{abstract}
Background: Airports exposed for many types of disaster that could cause MCI. It is essential for any airport to keep prepared for disasters and MCIs that could happen there. This study investigates the overall level of medical preparedness for MCIs at big Saudi airport.

Methods: This is a mixed-methodology study undertaken between February and March 2016. A semi-structured interview done with three members of the airport's disaster preparedness committee. KAP questionnaire regarding disaster/MCI preparedness distributed to all airport HCPs. Interview data summarized in tables, graphs and in a narrative manner. Mean, Median, Proportions calculated for study's quantitative variables.

Results: The airport had most of the essential provision needed for disaster preparedness, such as sufficient numbers of trained personnel for initial response, uniform triage system, uniform ICS, airport HVA. However, its lack of physiciandirected medical services, fatality management plan, cares in place plan, community involvement plan. KAP Survey Results: $64 \%$ of respondents were able to define MCI. Only $44 \%$ of participants were able to define MCIs preparedness. $85 \%$ knew what drills are. Only $61 \%$ of respondents knew that drills done at the airport. Only $47 \%$ knew that there was an on-going training. Only $29 \%$ of participants knew that airport disaster/MCIs plans periodically updated.

Conclusion: Typically, this airport does a moderately good job in the preparedness and planning for disasters/MCIs, and identifying the key preparing items for each category essential for preparedness. However, there are important provisions that tend to be lacking and levels of details that are missing.
\end{abstract}

Volume 6 Issue 3 - 2017

\author{
Salah Ezreqat, Anas Khan \\ Department of Emergency Medicine, King Saud University, Saudi \\ Arabia
}

Correspondence: Salah Ezreqat, Department of Emergency Medicine, College of Medicine, King Saud University, Riyadh, Saudi Arabia, Email sezreqat@gmail.com

Received: August 29, 2017 | Published: September 22, 2017
Abbreviations: MCI, mass casualty incident; AEP, airport emergency plan; KAP, knowledge, attitude, and practice; EIRRA, ems incident response and readiness assessment; NEMSMA, national emergency medical services management association; BSI, body isolation instrument; EMS, emergency medical services; PIO, public information officer; EOC, emergency operation center; MCP, mobile command posts; MEOC, mobile emergency operation center; $\mathrm{MoH}$, ministry of health; AAR, after action review; HVA, hazards vulnerability assessments; HCP, health care professionals

\section{Introduction}

Airports are vital national resources; they play a very important role in people and goods transportation at local, regional, national, international levels. In many ways, airports are the place of daily mass gathering, and there are few permanent residents at airports. Airports are exposed to many types of disaster that could cause MCIs, ${ }^{1}$ which would significantly create pressure on airport resources and require a surge in emergency medical services response. Furthermore, MCIs at the airport needs special arrangements and coordination with different jurisdictions. ${ }^{2}$ Airport emergency management is a complex process, which involves the participation of different agencies and jurisdiction. ${ }^{1}$ Study's airport is an international airport with more than 20million passengers and more than 160,000 flight operations. It is located $35 \mathrm{~km}$ away from the city, $23 \mathrm{~km}$ from the nearest trauma center. There are $3 \mathrm{MoH}$ clinics distributed through the airport, which are responsible for treating injuries, non-urgent medical problems and long-term management of chronic medical conditions for airport workers and passengers, also it's responsible for transferring those patients need for hospital admission by coordination with airport EMS. During MCIs and disasters, one of airport's mutual aid agreements hospitals plays a major role in incident management, in addition to $\mathrm{MoH}$ and Saudi Red Crescent. However, the airport has to follow the International Civil Aviation Organization's standards in MCI/ disaster response.

After the September terrorist attacks, disaster preparedness throughout the world has become a priority. ${ }^{3}$ Aviation accidents and disaster preparedness at airports remain global challenges as accidents continue to occur in different parts of the world. From airplane accidents, $68 \%$ happen during take-off or landing, thus, the area of concern is about $1 \mathrm{~km}$ in front of runways $500 \mathrm{~m}$ to the sides of taxi-ways, and $1 \mathrm{~km}$ behind. ${ }^{4}$ In the USA, all airports certified from federal aviation administration should have an Airport Emergency Plan(AEP). ${ }^{2}$ Most recently, three aviation disasters happened throughout the world; the first one was Istanbul Ataturk airport attack, which resulted in 41 dead and 239 injured on June 28, 2016. The second one was the Fly Dubai airline crash at Rostov-on-Don Airport, Russia, March 19, 2016, due to bad weather, which resulted in the killing of all 62 people on broad the aircraft. A third disaster happened at Zaventem airport, Brussels, Belgium, March 22, 2016, this resulted in 11 fatalities and 92 injuries. In Saudi Arabia, two major airplane accidents took place; the first 
one is the Saudi Airlines flight 163-airplane accident in 1980 at King Khalid International Airport (KKIA) in Riyadh during its stopover, which resulted in 287 fatalities. This accident was one of the deadliest single aircraft disasters in history. One of the factors that contributed to this fatal accident was the failure of the airport authority to ensure that its personnel had adequate equipment and training to function as required during an emergency. ${ }^{4-7}$ The second aircraft disaster happened at Jeddah, $2.8 \mathrm{~km}$ away from King Abdul-Aziz International airport in 1991; due to a mechanical error, which resulted in 261 fatalities. ${ }^{4}$ One more event happened at Saudi Arabia was the Russian plane hijacking after taking off from Istanbul to Moscow in March 2001, then the hijackers forced it to land at Prince Mohammed bin Abdel Aziz airport in Medina at 08:10 PM, to refuel the plane then continue flying to Afghanistan. 174 passengers and crew were on board. Hijackers were Chechen men wielding knives and claiming to have a bomb. Shortly after landing, 17 people freed-out the plane by hijackers, and other 15 escaped from the rear exits of the plane. After 17hours of negotiations between Saudi authority and hijackers, the Saudi authority decided to storm the plane. Minutes after the plane stormed; about six ambulances and fire engines surrounded the plane and more than 30members of the Saudi Special Security Forces Unit in full battle gear. Two Saudi air force cargo planes parked a few hundred meters(yards) away. Three deaths and seven people were injured; most of them were being treated for minor cuts and bruises. ${ }^{8}$ To keep airports(and any institution in general) well-prepared for MCIs and upgraded it to the international standards of preparation; ones need to conduct a continuous scientific evaluation for the current plans, programs, needs, hazards, equipment and human resources. Unfortunately, there is a scarcity of the published studies evaluating airports' medical disaster/MCIs preparedness. This study has two objectives:

i. To measure the overall level of airport medical preparedness for MCIs.

ii. To assess the current level of knowledge, attitude, and practice of the airport medical field workers toward disaster/ MCIs preparedness.

\section{Methodology}

This is a mixed-methodology study, done at a leading international airport in Saudi Arabia. Semi-structured group interview done with three members of the disaster preparedness committee the airport. The interview, which took approximately two hours, done in a meeting room in the Rescue and Firefighting department at the airport. Voice recording used, in addition, to note taking during the interview. Knowledge, Attitude, and Practice(KAP) questionnaire which is a quantitative method that provides access to quantitative and qualitative information, and it used to measure the degree of a known situation; provide new tangents of a situation's reality, improve the knowledge, attitude, and practices of specific themes; identify what is known and done about different health-related subjects, and create a reference value for use in future assessments and help measure the effectiveness of health education activities ability to change healthrelated behaviors. KAP questionnaire distributed to all HCPs who are working at the airport $(\mathrm{N} \approx 50)$; they were physicians, nurses, paramedics and technicians. The study conducted during the months of February and March 2016. Data collected in the interview using a modified copy of "The EMS Incident Response and Readiness Assessment (EIRRA) tool". Which is a tool developed in 2011 by a multi- disciplinary team led by the National Association of State Emergency Medical Services Officials(NASEMSO), The project was conceived following the release of the investigation results by the National Transportation Safety Board(NTSB) of the 2008 Mexican Hat, Utah, motor coach crash. The tool is available and has an open access. ${ }^{9}$ After the pilot study which was done with the disaster preparedness coordinator at King Khalid University Hospital (KKUH) and after supervisor revision; a simple modification was done on the tool to make it more suitable for our research. Added new items and question to the tool such as the existence of evacuation plan, and shelter in place plan in reference to the operational templates and guidance for EMS mass incident deployment, 2012, which is developed for the U.S. Fire Administration (USFA) by the National Emergency Medical Services Management Association (NEMSMA). ${ }^{10}$ It was comprised of 7 categories and 33 indicators. The categories are the broad components necessary for the system preparedness, while indicators are sub-components of the categories. The seven categories consist of resources or activities that are essential for optimal emergency medical dispatch, EMS system, and emergency care/hospital response in the MCI. These seven categories are personnel, infrastructure, emergency care system, public awareness and notification, evaluation, mass casualty planning, and governance.

Simply modified copy of KAP questionnaire, which was used in similar studies done to assess the knowledge, attitude, and practice of health care workers regarding disaster preparedness at hospitals. ${ }^{11-13}$ We piloted the questionnaire on 8 paramedics working at KKUH/ Emergency Department(ER) before using it at the airport; based on the pilot result and expert revision, simple modifications were done on the questionnaire to be more suitable for our research. These modifications were mainly in the demographics and replacing the question asking about definition of the disaster, with similar question asking to define the MCIs, other question asking if there is a difference between disaster and MCIs in knowledge section, and question asking about if there is past experience in participation in responding to a real disaster in attitude section. Approval to conduct the study granted officially from the airport administration, and IRB approval was taken from King Saud University College of Medicine. Informed consents distributed to all participants and most of them signed it. The questionnaire did not ask for names of the participants or any identifiable information. Voluntariness, understanding of information and disclosure of information was encouraged. The name of the airport was not mentioned in the publication due to bureaucratic and security reasons. Mean, Median, Proportions calculated for study's quantitative variables. To study the association between demographic data and participants' knowledge, attitude, and practice; we used chisquare test or Fisher's exact test for categorical data. For continuous data, student t-test or Mann-Whitney u test used for two groups and analysis of variance or Kruskal-Wallis test for more than two groups, but due to small sample size; a few assumption were made based on the analytical tests. All tests were done using SPSS version 21. Regarding qualitative data, which is a pure description of the current level of airport MCI preparedness, it was enough to present the data in a narrative manner and summarize it in tables and graphs, and compare it with the international standards of MCI preparedness and other studies results.

\section{Results}

A. Personnel: Airport disaster committee recognizes that these numbers of personnel are just sufficient to meet the initial response for 
disasters and MCIs until the arrival of external support. Regarding community involvement(volunteers), there were no previous or current plans to include the community in the disaster plan. Furthermore, there is no clear plan for effective using of bystanders on the scene during the incidents. Regarding medical personnel numbers at the airport during study conduction period, there were:

i. 12 workers at the level of basic life support(BLS)

ii. 5 specialized paramedics(seniors with ALS)

iii. 25 medical staff(nurses and physicians) at $\mathrm{MoH}$ clinics

\section{iv. 1 hazmat specialist}

v. 230 rescue/extrication members who are holding a diploma level in Rescue and Firefighting.

vi. 10 Ambulance Attendance who are drivers with first aid levels, so they can help in case of MCI's

Most of EMS personnel trained on incident command and mass casualty management and they certified by General Authority of Civil Aviation at its HQ in Jeddah. In the other side, the training of emergency personnel in using alternative communication methods(diagrams, devices, translation service, emergency information forms-EIF, etc.) for children and other patients unable to communicate their medical history, is not available at this time; but there is a plan to do it soon. There are safety policies established for emergency personnel such as Body Isolation Instrument (BSI) precautions, how to use lights and sirens response, and determining scene safety before approaching. Mutual aid plans and agreements established with the surrounding jurisdictions. Regarding the medical direction of personnel during MCIs, the committee stated that it will be the responsibility of airport local Emergency Medical Services(EMS), until the arrival of surrounding hospital support teams who are responsible for taking lead upon their arrival. They stated that Airport's EMS directed by a senior paramedic, not a licensed physician.

B. Infrastructure: They mentioned that there is a call center at airport that is responsible for answering all emergency calls to a unified telephone number for police, firefighting, and ambulance services within the airport campus(that is not the case in Saudi Arabia, where each of police, civil defense "fire-fighters), and ambulance have a separate number and dispatchers). In the airport, the emergency number used is a local number containing regular seven digits designated only in the airport; but it was not well distributed throughout airport facilities -which we went through during our visits to the airport- to ensure easy access in case of emergency. Regarding public and media communication during MCIs, these services were provided by Public Information Officer (PIO) at the airport. There were two types of command centers; a permanent command post (PCP), or an Emergency Operation Center (EOC) which is located inside the airport terminal building, and mobile command posts(MCP) or Mobile Emergency Operation Center(MEOC), which are provided with dispatchers used in transmitting a continuous information and on-scene video from the scene to the PCP where communication with leaders, public, media, and other hospitals takes place. Not all emergency dispatchers are provided with the ability to determine caller location (GPS); only the new devices are provided have such capability. In the same focus, the airport disaster/MCIs plan had a system for early notification of hospitals, and another system for continuous bed status monitoring; this system managed in coordination with
EOC of Ministry of Health $(\mathrm{MoH})$. There are an ample number of program and interoperable two-way radios for use by emergency responders in MCIs, emergency responders also equipped with wireless phones (Bravo phones), but there is a lack of satellite phone to be used in a situation where wireless coverage is limited. These communication equipment are tested regularly in a semi-daily manner (once per day), mainly for any mechanical defects rather than testing every channel or verifying interoperability that may be used in case of MCIs. Airport emergency medical services in coordination with airport security system have evaluated and planned:

\section{i. Access to/from locations where MCIs may occur}

ii. How to manage/re-route traffic and bystanders to keep a scene safe during MCIs; this plan is included in the Table-Top exercises.

Plans for vehicles and personnel staging during MCIs are included in the airport disaster plan and it has been exercised. The staging area is not pre-defined area; especially for aircraft crashes, because it occurs in different locations. There is no plan to cover the collection area(the area which serves as an assembly area before initiating the triage area) by using umbrellas or big size tents; to protect victims from the hightemperature weather in Saudi Arabia, prevent sunburns and sunstroke; but they have this plan for the triage area. Planning for the transport of special equipment and supplies (e.g. blood, medication, etc.) needed in MCIs is included in the plan but not exercised. Regarding essential equipment that may be needed during MCIs, the airport has a well-stocked patient care equipment, supply, extrication, towing and recovery, and personal safety equipment. There is a plan for inventory resources management (sustainability), the plan is to keep 200\% (of the required resources for the largest airplane crash) ready in term of renewable resources. In the opposite, the plan for "care in place" in lieu transport to the hospital is not initiated by airport local EMS. Indeed, their role falls into triaging and stabilization of patients until transporting them to the hospitals, or until the arrival of support from the "coordinating hospitals".

A. The emergency care system: Emergency care system at airport consisted of 3 clinics for employees' health and passengers' health; also there were 5 stations for first aid distributed throughout the airport. It's important to mention that airport lack for a system which outlines the regionally designated hospitals and specialty care centers (e.g. trauma centers, burning centers, etc.).

B. Public awareness and notification: There is a good system for public notification during incident which includes notification to entire airport system(e.g. sirens, electronic posts, etc.); and community alert systems such as using of overhead announcements, message boards, emails, social media, etc., and system for media engagement for public notification during MCIs. Emergency public information is provided via the PIO, who is a member in the airport ICS.

C. Evaluation: There was an evaluation system providing for a periodical review of the performance of emergency responders at MCIs. This system depends on "After Action Review"(AAR), which used in the system improvement plan. However; evaluation system lacks for a robust and reliable electronic information system, which can facilitate access and analysis of data, and could be used in patients' identification and tracking.

D. Mass Casualty planning: There was a uniform incident command system, uniform triage system, multi-jurisdictional agreement that 
delineate "who is in charge, and who participates. Initial special Hazards Vulnerability Assessments (HVA) is addressed in the airport disaster plan and it's updated annually; all threats identified in HVA are not included in the annual airport drills. However, they are just exercising aircraft crashes and building collapse (evacuation). There is no planning for multiple fatality management included in the airport disaster plan. Evacuation planning is included in the plan, and it exercised every other year. Shelter in place planning was included in the plan also but is not included in the exercise as well.

E. Governance: In the case of MCIs, the roles and lines of authority have clearly defined among local and national governing bodies, and it included in the exercise. There was funding mechanizes for disaster response planning, exercising, and another cost of preparation. Furthermore, there is a plan for disasters/MCIs that have a broad implication (e.g. across other cities, airports) such as weather changes, or sands storm; but it needs to be updated regularly.

F. After each category; participants were asked about their perceived institution preparedness for MCIs in term of each given category. They perceive that airport preparedness for MCIs is around 70$80 \%$ for most of category included in the tool; except for Governance category they perceive that it is around $90 \%$ prepared. The following figure shows all categories with perceived preparedness.

\section{Demographic data}

Out of 50 questionnaires which were left with the secretary of the firefighting department and airport clinics be distributed to all the HCPs $(\mathrm{N}=50)$ at the airport ( $\mathrm{MoH}$ clinics and paramedics staff) during the period of March 1-10, 2016. There were 34 HCPs (68\%) who filled the questionnaire, $2(4 \%)$ refused, $4(8 \%)$ didn't complete the questionnaire, and 10(20\%) were not available (in vacations). From those $34(68 \%)$ who responded to the questionnaire; there were $22(64.7 \%)$ male respondents, $12(35.3 \%)$ female respondents (Figure 1). 38.2\% of respondents were aged less than 30years, the mean age for all respondents was 36years old. 5(14.7\%) respondents held secondary(high-school) education level, 13(38.2\%) for bachelor or diploma(certificates) levels, $2(5.9 \%)$ had master level in nursing, and $1(2.9 \%)$ had $\mathrm{PhD}$ level. There were nurses $13(38.2 \%)$, then 9 paramedics $(26.5 \%)$, then 7 physicians $(20.7 \%)$, and finally 5 emergency medical technicians(EMTs)(14.7\%) (Figure 2). There were 9 respondents $(26.5 \%)$ working in the airport for 1-5years and 10 -20years each, $8(23.5 \%)$ respondents were working for less than 1 year, 5(14.7\%) were working for 5-10years, and 3(8.8\%) were working for 20-30years (Figure 3).

\section{Knowledge}

Questions addressed in this section were to assess whether airport's healthcare workers knew what MCIs is, what a disaster/MCIs preparedness is, whether they knew if there is a difference between disaster and MCIs, where to find the plan, whether staff members understood their function during a drill. Starting with the definition of MCIs; out of 34 participants, there were $22(64.7 \%)$ who were able to define MCIs correctly; their definitions were ranged between: "an incident that involves a lot of victims and deaths", to "any incident in which EMS resources such as personnel and equipment are overwhelmed by the number and severity of casualties". The other $12(35 \%)$ participants were left it blank. Out of these 12 participants, there were $7(58 \%)$ nurses (all of them holding diploma level),
$2(16.5 \%)$ physicians, and $3(25 \%)$ were technicians. There were $15(44 \%)$ participants who were able to define MCI preparedness, their definitions were around "having a fully structured plan in place where MCIs could occur, in order to effectively deal with incidents, by having a well-trained personnel and well-equipped facilities". Out of other 19(54\%), there were 14 participants who left it blank and 5 participants who defined MCIs preparedness incorrectly (most of them define MCI preparedness with the same definition of MCI event). The majority of participants $25(73.5 \%)$ said that there is a difference between disasters and MCIs in term of definition, post occurrenceeffects, and required resources to overcome the event; most of them were male participants $(\mathrm{P}=0.015)$, while $5(14.7 \%)$ said no difference and $4(11.8 \%)$ don't know. $79 \%$ of the participants knew where to find airport disaster/MCIs plan. Participants who had been working at the airport for 10-20years showed better knowledge about "where to find airport disaster plan" than other HCPs at an airport $(\mathrm{P}=0.028)$. Most of the participants $(85.3 \%)$ knew what the drills are; paramedics and nurses showed better knowledge regarding what drills are than other HCPs at the airport $(\mathrm{P}=0.017)$. More than half of participants $(61.8 \%)$ said that staff members understand their functions during drills, where less than third (29.4\%) said that staff members don't understand their functions during drills, and $8.8 \%$ of participant didn't know (Figure 4).

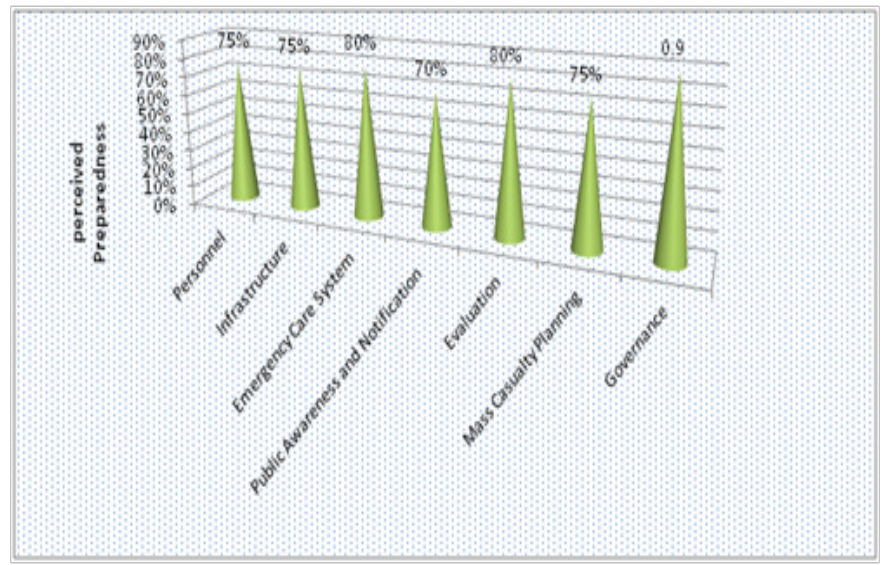

Figure I Disaster management committee members' perceived preparedness regarding the seven preparedness categories.

\section{Gender}

\section{Male afemale}

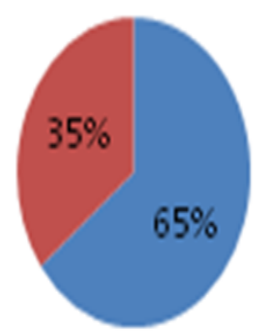

Figure 2 Proportion of study participants according to their gender. 


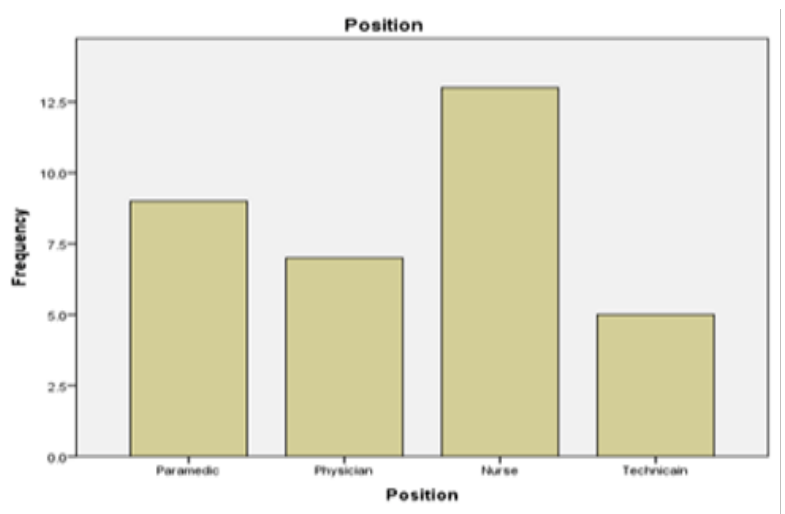

Figure 3 Proportion of study participants according to their positions.

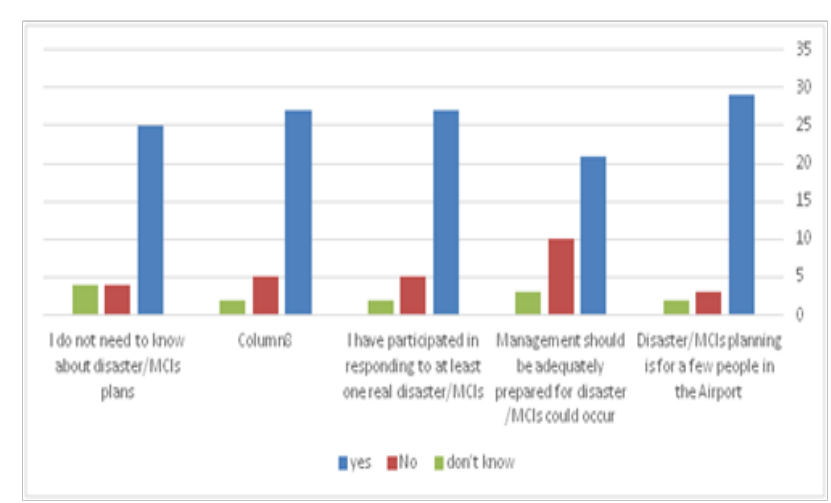

Figure 4 Airport HCPs' knowledge regarding disaster/MCl preparedness.

\section{Attitude}

$76.5 \%$ of participants said that they need to know about airport disaster/MCIs plans, while $17.6 \%$ of participants think that they don't need to know about these plans, and $5.9 \%$ were unsure. More than half of $(52.9 \%)$ have participated in responding to at least one real disaster/MCI during their career life; male participants participated more in responding to real disasters/MCIs than female $(\mathrm{P}=0.003)$. Moreover; Paramedics had more participation than other HCPs at an airport in responding to real disasters $(\mathrm{P}=0.014)$. $20.6 \%$ of airport HCPs didn't participate in responding to such real events, and $26.5 \%$ were unsure about their participation status. 32 participants $(94.1 \%)$ said that management should be adequately prepared for disasters/ MCIs which could occur at the airport, were the rest 2 participants said that management shouldn't be adequately prepared for disasters/ MCIs which could occur at the airport. The majority of participants $(29,85.3 \%)$ disagreed with "disaster/MCI planning is for few people at the airport. Regarding the pre-identification of potential hazards that could occur at the airport; the majority of the participants (91\%) agreed on that. In responding to the question asking about the necessity of having disaster/MCIs plans; 33 participants (97.1) agreed that is necessary. Nurses and paramedics showed better attitude regarding that "potential hazards likely to cause disaster /MCIs should be identified and dealt with" than others $(\mathrm{P}=0.013)$.

Regarding the probability of disasters/MCIs to occur at an airport; $97.1 \%$ of participants believed that it's unlikely to occur at the airport, while 1 participant was unsure. 15 participants(44.1\%) agreed that disaster/MCIs management is for airports directors and mutual aids only, while 14 participants(42\%) disagreed on that, and 5 were not sure. 29 participants( $85.5 \%)$ disagreed on that "disaster/MICs simulations should occur frequently in the airport", while the rest participant agreed. On the other way, 25 participants $(73.5 \%)$ believed that drills should occur at the airport, while 7 participants (20.5\%) disagreed on that, and 2 participants were unsure. However; EMTs showed better attitude regarding conduction of drills at the airport than other $(\mathrm{P}=0.013)$ (Figure 5).

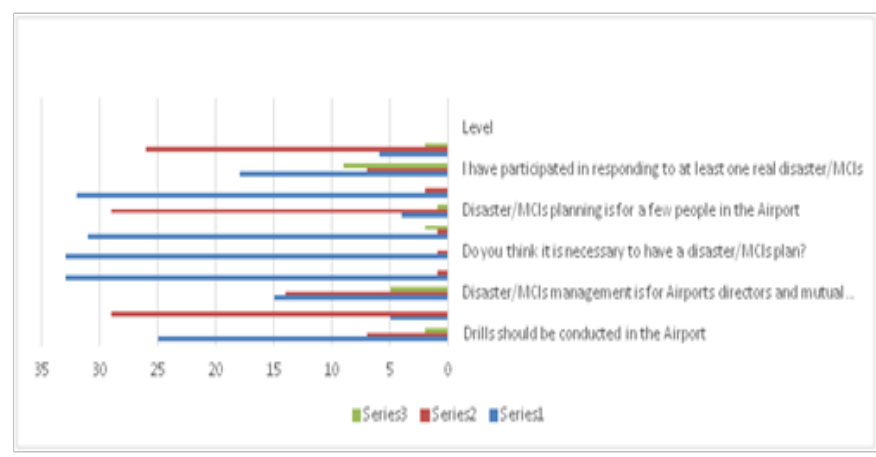

Figure 5 Attitude of HCPs at airport regarding disaster/MCls preparedness.

\section{Practice}

In responding to a question asking about if the disaster drills are done at the Airport; there were 21 participants (61.8\%) said yes, 9 participants $(26.5 \%)$ said no, and 4 participants (11.8\%) didn't know. Out of those participants who said yes(21 participants); 6 participants(28.5\%) said that the type of drills done at Airport is aircraft crashes drills, were 7 participants said that drills done at Airport are aircraft crash and building evacuation drills. Participants were asked about if there is an on-going training at the Airport; there were 16 participants $(47.1 \%)$ said yes, 10 participants $(29.4 \%)$ said no, and 8 participants $(23.5 \%)$ didn't know. The last question in the practice section was asking if the disaster/MCIs plans are periodically updated; there were 10(29.4\%) participants who said: yes, it's updated periodically, and 11 participants $(32.4 \%)$ said no, while 13 participants (38.2) didn't know if it updated regularly or not (Figure 6).

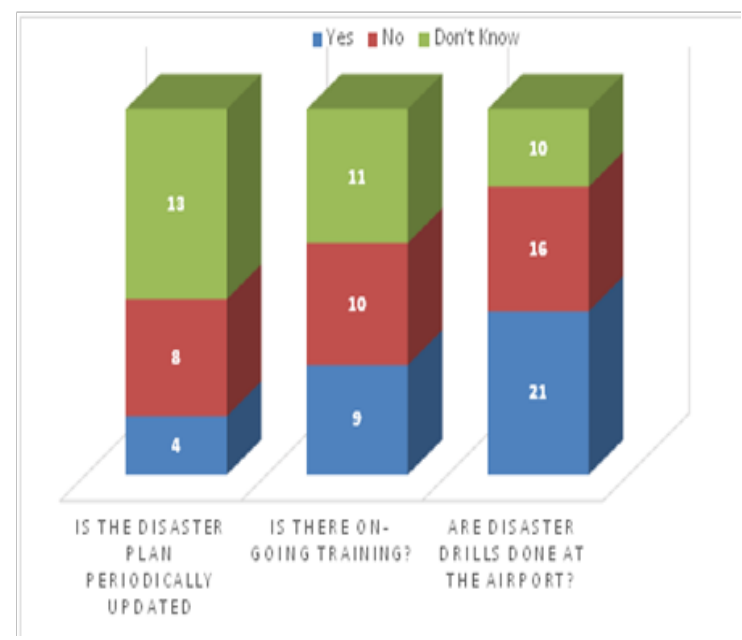

Figure 6 Airport HCPs practice regarding disaster/MCls preparedness.

\section{Discussion}

Starting with personnel: As the head of Firefighting department said that there were sufficient numbers of emergency personnel for 
initial response in cases of MCI. There is no specific standard for minimum medical personnel numbers required for Airports. However, as mentioned in ACRP report; ${ }^{2}$ Airports should have sufficient numbers of EMS personnel enough to respond to incidents involving maximum numbers of persons that can be carried on the largest airplane that lands at the airport. While airport EMS are directed by a senior paramedic, not a physician; the American College of Emergency Physicians(ACEP) indicated that all EMS aspects require an active involvement of identifiable board-certified emergency physician to be an EMS medical director, to ensure high-quality patient care and to achieve the responsibilities of involving continues design, operation, evaluation and revision of EMS system to guarantee patient access to definitive patient care. ${ }^{14}$ Study airport has most of the required equipment and infrastructures necessary for disaster/MCIs response. Also, it has two types of command posts; mobile and permanent. On the flip side, many airports need to set up such emergency operation centers. ${ }^{2}$ Communication hardware in study airport was available in sufficient numbers and tested regularly for mechanical defects; the same was among USA airport. ${ }^{2}$ In contrast; Taiwan's Chiang KiaShek (CKS) airport was lacking for a good maintenance system for communication hardwires, which resulted in the technical failure of the radio handsets used during MCI. ${ }^{15}$ The study airport has a plan for evacuation and staging of vehicles and personnel, and it exercised it regularly as airport general disaster preparedness committee indicated during the interview, while some of USA airports included in their plans information illustrating conditions requiring evacuation, with less information about location of collection areas and how evacuation process will be supervised. ${ }^{2}$ A study done by Graham, et al. and his colleague, in 2005 to evaluate USA schools preparedness for MCIs as points of daily mass gathering; they found that $95 \%$ of schools participated in the study have an evacuation plan, but $30 \%$ of them never conducted drills. ${ }^{16}$ It's important to have a plan for transport of special equipment and supplies(e.g. blood, medication) needed in MCIs; but it's more important to test these plans regularly to avoid any challenges could occur during MCIs. ${ }^{2}$

Study airport lacks an effective plan for "care in place" by its own personnel, they depend on external jurisdiction to do such job upon their arrival; as mentioned before that the nearest hospital to the airport is $23 \mathrm{~km}$ far away, it's in the middle of downtown, and they have no clue on any such agreements. In MCIs you are required to provide an immediate medical care for victims to prevent any further complications which might increase the need for resources, and it could increase the number of mortalities. The Same scenario happened while dealing with Singapore airline crash MCIs in 2000; lacking of effective "care in place plan" led to more morbidities and mortalities. ${ }^{15}$ Moreover, after Boeing 727 aircraft crash in 1975 at John F. Kenedy International Airport(JKI) in New York City, which crashed on approach due to thunderstorm during its way from New Orleans to New York City and its resulted in killing of six of the eight crew members and 107 of the 116 passengers; a new concept of "care in place" were added to New York City airports, which involve establishing a new equipment known as Emergency Mobile Hospital at airports which were a two vehicles providing two operating rooms, 12 monitored ICU beds, a 16-bed burn unit, and 72 other beds to be used for on-site stabilization of critically ill patients, before transfer to a definitive care facility. ${ }^{17}$ Study airport designated a dedicated PIO, who is responsible for public awareness and notification and handling media inquiries during and post MCIs. In contrast, some of USA airports were lacking for a designated PIO. ${ }^{2}$ As known, command and control are one of the most important parts of a coordinated response. Study airport met the standard of coordinated response; which is a unified command system, unified triage, and pre-identified policy to determine who in-charge with the responding agencies. ${ }^{2}$ In contrast, during Singapore airline crash 2000, firefighters were focusing on firefighting and they didn't establish the medical command system. They were depending on physicians and nurses who were not trained or prepared for incident command; this led to creating a chaotic response. Like most other airports in the USA; study airport has established a comprehensive airport HVA, but they just focus on aircraft crashes and building evacuation in their exercises. Yet, it is better for every airport to include all possible risks into disaster planning and exercises. Moreover, exercises at study airport are done just during normal weather and during day time in a fixed time every year. Having the drills in the most convenient time of the day and year would give a false implication on the preparedness level. Disasters have more probabilities to happen during bad weather and it's could occur at night and at any time throughout the year. Singapore airline crash 2000 happened at night $(23: 18 \mathrm{pm})$ with a bad weather, although it has happened after four months following revision, testing, and exercising of the airport MCI plan; the response was not effective, and MCI management was very bad. One important factor led to this situation was the absence of personnel experience to work during the night and bad weather. ${ }^{15}$

Study airport lacks for fatality management plan; MCIs and disasters could result in the death of a substantial number of people. ${ }^{18}$ Thus, the airport should have a plan for fatality management and must recognize the importance of medical examiner(mortuary) in the identification of the deceased and the notification of relatives(nextof-kin) during and after disasters. ${ }^{2}$ Participants, KAP survey were slightly knowledgeable about: what disaster is, $64 \%$ defined it correctly, the difference between disaster and MCIs(73.5\%), where to find disaster/MCIs plans, and what drills are. With poor knowledge about the definition of disaster/MCI preparedness (more than half of the participants $56 \%$ didn't know what disaster/MCI preparedness is). In general; our study has found that airport HCPs have a partially good level of knowledge toward disaster/MCIs preparedness with some deficiency in some areas; which provide them with the basic and underlining knowledge regard disaster/MCI preparedness. The overall attitude of study participants toward disaster/MCIs preparedness was good. As airport health workers recognize the importance of disaster/ MCIs preparedness; this will be reflected in their medical practice in the case of disaster. Unfortunately, there is a noticeable deficiency in airport HCPs' practice toward disaster/MCIs preparedness, this might be due to less engagement of airport workers in the annual drills done at the airport, or there is a defect in announcing or posting for such important exercise at airport facilities. A study was done by moabi to assess HCPs knowledge, attitude, and practice regarding disaster preparedness at Johannesburg hospital in South Africa, 2008 found that HCPs at Johannesburg Hospital were aware of disaster preparedness and management, and they had a positive/good attitude toward disaster management; but their practice was poor and need for improvements especially in regard to ongoing training, performance of drills and the frequency of regular updating of the plans. ${ }^{11}$ Jordanian nurses'(general nursing) knowledge, skills, and preparedness toward disaster preparedness were tested from their own perception in a national wide study in 2011; the study found that Jordanian nurses' knowledge, skills, and preparedness toward disaster preparedness need for continuous reinforcement to assure self-efficacy for disaster management. ${ }^{19}$ A cross-sectional study was done by Fatma. A to assess Saudi nurses' knowledge, attitude, practice, and familiarity regarding disaster preparedness 2014; she found that Saudi nurses were lacking for knowledge and practice of disaster preparedness, 
with an acceptable level of attitude and neutral level of familiarity regarding disaster preparedness. ${ }^{13}$ This study had several limitations:

i. Limited generalizability because it was based on one designated airport.

ii. Not all airport HCPs were able to participate in the KAP survey, in addition to the small population sample.

iii. Information given could not be assessed for accuracy or validity, as most interviews and KAP studies.

\section{Conclusion \& recommendations}

Typically, Study Airport do a moderately good job in the preparedness and planning for MCIs, and identifying key preparing items for each category essential for preparedness, as they have: Sufficient numbers of trained personnel, ample numbers of communication hardware, unified ICS, Unified triage system, permanent and mobile command center, and an evacuation plan, traffic management plan. However, there are important provisions that tend to be lacking and levels of details that are missing; which involve: non-physician medical direction, lack of some important plans such as care in place plan and fatality management plan, lack of comprehensive training plan which include all personnel at the airport to increase their KAP related to MCIs/disaster. In addition to the need for more studies targeting airports and their preparedness for disasters and MCI in the future; our study results suggest a number of recommendations for airports. Most of them are specifically for study airport, while other similar airports can benefit from these recommendations also. These recommendations include:

a. Make sure that non-aviation incidents and disasters (e.g. severe weather, active shooter, hostage situation, and terrorist attack, etc.) are involved in the overall airport disaster plan, and to exercise it on a regular basis.

b. Recognize the importance of having and exercising the following plans in order to strengthen airport response plan for emergencies: Care in place plan, Fatality management plan, Community engagement plan, Resources transportation plan, and Shelter in place(exercising)

c. Guarantee that all airport workers, not only EMS workers are involved in the disaster /MCIs training plans and disaster/MCIs related activities which are done at the airport or at the surrounding communities.

d. Establish a program which aims to make airport worker knowledge, attitude, and practice better.

This program might be one of the following:

i. Establish continues disaster/MCIs education program inside the airport, and keep it open for all airport employees.

ii. Enforce airport employees to attend a specific number of disaster-related Continuing Medical Education (CME) hours every year.

e. Airport authority should recognize the importance of converting from non-physician medical direction to licensed physician medical direction for those disaster/MCIs related planning and activities.

\section{Acknowledgements}

None.

\section{Conflict of interest}

Author declares that there is no conflict of interest.

\section{References}

1. Smith JF. Airport disaster preparedness in a community context. American Public University System, USA; 2009:1-57.

2. Stambaugh H. An Airport Guide for Regional Emergency Planning for CBRNE Events. Transportation Research Board. USA, 2009:1-43.

3. Fischer P, Kabir K, Weber O, et al. Preparedness of German paramedics and emergency physicians for a mass casualty incident: a national survey. Eur J Trauma Emerg Surg. 2008;34(5):443.

4. Aviation Safefty network. Flight Safety Foundation, Saudi Arabia; 1980.

5. SBR. Statistic Brain. USA; 2016.

6. Sheikh Nasser Al-Assaf HE. Aircraft Accident Report: Saudi Arabian Airlines, L-IOll, HZ-AUK, Flight 163 Riyadh, Saudi Arabia on August 19, 1980. Presidency of Civil Aviation, Saudi Arabia; 1982. p. 1-196.

7. Thomson J. Human Behaviour in a Crisis-the Saudia 163 Accident, 1980. Saudi Arabia; 2013. p. 1-6.

8. MailOnline. Three dead as Saudis storm hijacked plane. UK: Associated Newspapers Ltd; 2001.

9. NASEMSO. EMS Incident Response and Readiness Assessment: A self-assessment tool to measure the level of EMS preparedness for responding to a highway mass casualty incident or other large scale emergency. USA; 2011. p. 1-72.

10. FEMA. Operational Templates and Guidance for EMS Mass Incident Deployment. USA; 2012. p. 1-168.

11. Rosemary Maud Moabi. Knowledge, attitudes and practices of health care workers regarding disaster preparedness at Johannesburg hospital in Gauteng Province. South Africa; 2009. p. 1-64.

12. Adenekan BA, Balogun MR, Inem V. Knowledge, attitude, and practices of emergency health workers toward emergency preparedness and management in two hospitals in Lagos. J Clin Sci. 2016;13(1):23-28.

13. Ibrahim FAA. Nurses Knowledge, Attitudes, Practices, and Familiarity Regarding Disaster and Emergency Preparedness-Saudi Arabia. Am J Nurs Sci. 2014;3(2):18-25.

14. Medical Direction of Emergency Medical Services. Clinical \& Practice Management, USA. ACEP. 2016.

15. Lee $\mathrm{WH}$, Chiu TF, $\mathrm{Ng} \mathrm{CJ}$, et al. Emergency medical preparedness and response to a Singapore airliner crash. Acad Emerg Med. 2002;9(3):194-198.

16. Graham J, Shirm S, Liggin R, et al. Mass-casualty events at schools: a national preparedness survey. Pediatrics. 2006;117(1):e8-e15.

17. Dove DB, Del Guercio LR, Stahl WM, et al. A Metropolitan Airport Disaster Plan-Coordination of a Multihospital Response to Provide On-site Resuscitation and Stabilization before Evacuation. J Trauma. 1982;22(7):550-559.

18. Adler J. Mass casualty management in earthquakes and air crashes. Isr Med Assoc J. 2002;4(5):373-374.

19. Al Khalaileh MA, Bond E, Alasad JA. Jordanian nurses' perceptions of their preparedness for disaster management. Int Emerg Nurs. 2012;20(1):14-23. 